\title{
Clinicopathological characteristics of extranodal follicular dendritic cell sarcoma: A report of two cases
}

\author{
$\mathrm{XING} \mathrm{ZHAO}^{1 *}$, DAYONG SUN ${ }^{2 *}$ and GANG ZHANG ${ }^{3}$ \\ ${ }^{1}$ Department of Pathology, Affiliated Hospital of Chengde Medical College, Chengde, Hebei 067000; \\ ${ }^{2}$ Department of Tumor Radiation and Chemotherapy Center, Chengde Central Hospital, Chengde, Hebei 067000; \\ ${ }^{3}$ Department of General Surgery IV, Baoding First Hospital, Baoding, Hebei 071000, P.R. China
}

Received March 3, 2020; Accepted November 20, 2020

DOI: $10.3892 / 01.2021 .12443$

\begin{abstract}
Follicular dendritic cell sarcoma (FDCS) is an extremely rare tumor, which mainly originates from FDCs in the lymph nodes. Sometimes FDCS can arise from outside the lymph nodes due to the existence of acquired lymphoid tissue, which becomes the histological basis of the tumor. The diagnosis of FDCS, particularly extranodal FDCS, presents a challenge for pathologists and hematopathologists. The present study presents two cases of extranodal FDCS based on clinical features and histomorphology. Soft tissue of the chest wall was involved in case 1 and right tonsil tissue in case 2. Case 1 underwent surgery, and was in good health post-operatively. During the 5-month post-operative follow-up period, the patient was healthy in all respects. Case 2 received surgery combined with radiotherapy, and the follow-up data reported that the patient remained alive, without signs of recurrence or metastasis during the 4-month post-operative follow-up period. Additionally, a total of 102 cases of extranodal FDCS were retrieved from the literature, which were extracted and reviewed carefully. The rates of recurrence, metastasis and mortality were 14.63 (12/82), 17.07 (14/82) and 8.29\% (15/82), respectively. The overall survival rates of the 102 cases, showing 2-year total survival rates, were $70 \%$, the same with that of 5-year total survival rates. The 2-year tumor-free total survival rates were $68 \%$, and the 5 -year equivalents were $32 \%$. Female patients had a poorer prognosis than male patients $(\mathrm{P}<0.05)$. Kaplan-Meier estimation presented no statistically significant differences between disease-free survival rates or overall survival rates and age, tumor size or treatment $(\mathrm{P}>0.05)$.
\end{abstract}

Correspondence to: Professor Gang Zhang, Department of General Surgery IV, Baoding First Hospital, 320 Zhonghua Road, Baoding, Hebei 071000, P.R. China

E-mail: 23131675@qq.com

*Contributed equally

Key words: extranodal, follicular dendritic cell sarcoma

\section{Introduction}

Histiocytic neoplasms are a type of tumor that arise from the monocyte-macrophage system, including dendritic cells (DCs), macrophages and sometimes histiocytes $(1,2)$. DC tumors are associated with certain types of antigen-presenting cells (2). Follicular DC sarcoma (FDCS) is extremely rare, so its epidemiology is unclear. There is a wide patient age range, with an adult predominance (median patient age, 50 years) and an almost equal sex distribution $(2,3)$.

FDCS consists of a neoplastic proliferation of spindled to ovoid cells exhibiting morphological and immunophenotypic features of FDCs (1). Misdiagnosis occurs frequently, due to the fact that it has the same micromorphology as other common neoplasms, such as other types of sarcoma and lymphoma $(2,3)$. In $\sim 35 \%$ of cases, FDCS presents in the lymph nodes (commonly in cervical nodes), while $\sim 65 \%$ of cases present with extranodal disease $(1,4,5)$. A number of extranodal sites can be affected, such as tonsils, gastrointestinal tract, soft tissue, mediastinum, retroperitoneum, omentum and lungs $(2,3)$. Surgical excision is the main treatment, sometimes combined with adjuvant radiotherapy or chemotherapy (3). The 2-year survival rates for early, locally advanced and distant metastatic diseases are 82,80 and $42 \%$, respectively $(1,2)$. Some patients may die from refractory paraneoplastic pemphigus (2). Inflammatory pseudotumour-like FDCs or fibroblastic DCs often affect the liver or spleen in female patients $(1,2)$. Histologically, the neoplastic-spindled cells are dispersed within a prominent lymphoplasmacytic infiltrate (1). In the present study, two cases of extranodal FDCS were reported, which affected the tonsils and soft tissue of the chest wall were collected. Additionally, an analysis of 102 cases of FDCS from the literature was performed to further explore the biological behavior of extranodal FDCS.

\section{Case report}

Samples. The present study retrospectively reviewed all cases of extranodal FDCS in the past 5 years, including excision surgery and biopsy, a total of two cases were collected from the pathological archives of the Affiliated Hospital of Chengde Medical College (Chengde, China) between January 2013 and January 2020. Two experienced pathologists reviewed all the 
slides of the two cases independently, identifying the diagnosis. Case 1 was further reviewed and confirmed by the pathologists of the Department of Pathology of the China-Japan Friendship Hospital (Beijing, China). The case history was consulted to collect the corresponding clinical data. Additionally, two experienced radiologists were asked to confirm the preoperative imaging test. The two patients were recommended routine re-testing monthly and were followed up until now (followed for 4 and 5 months, respectively), and all the information was recorded.

Histological examination. Tissue specimens were collected for $10 \%$ buffered formalin fixation, grossing, routine dehydration, embedding into paraffin and sectioning into $4-\mu$ m-thick sections for hematoxylin and eosin staining (10\% buffered formalin for $12 \mathrm{~h}$ at room temperature; hematoxylin for 5-15 min at room temperature; water for 1-3secat room temperature; $1 \%$ acid alcohol for $1-3 \mathrm{sec}$ at room temperature; and eosin for 1-3 min, at room temperature). Microscopic and immunohistochemical phenotypes were observed to ensure the accuracy of the diagnosis, according to the diagnostic criteria of the 2017 World Health Organization (WHO) Classification of Tumors of Haematopoietic and Lymphoid Tissues (5).

Immunohistochemistry (IHC). IHC was performed on paraffin blocks, using the Leica automatic immunostaining device (Leica Microsystems, Inc.). The 4- $\mu$ m-thick sections were fixed using $10 \%$ buffered formalin for $12 \mathrm{~h}$ at room temperature. All monoclonal antibodies used were purchased from OriGene Technologies, Inc., and are listed in Table I. The known positive tissue was used as the positive control, and PBS as the negative control. The scoring method based on both the intensity ( 0 , no staining; 1 , weak staining; 2 , medium staining; and 3, strong staining) and proportion of positive cells $(0,0 \% ; 1,1-25 \% ; 2,26-75 \%$; and $3,76-100 \%)$. The final staining scores were calculated by multiplying the staining intensity score by the extent of staining score. A final staining score of $\geq 3$ was considered positive, and others were classified as negative.

\section{Case description}

Case 1. A 63-year-old male patient visited the doctor presenting with a chest wall neoplasm without any complications in September 2019. He had no weight loss, pain, fever or other feeling of discomfort. Physical examination revealed a mass lesion measuring $5 \times 4 \mathrm{~cm}$ under the skin of the chest wall. No palpable lymphadenopathy was found. The patient was suggested to undergo surgery to resect the mass. Grossly, the resected tissue with skin measured $6 \times 5 \times 1.5 \mathrm{~cm}$. A white nodule measuring $\sim 4.5 \times 4 \mathrm{~cm}$ was found, with a complete capsule and firm quality. Some gray regions were observed on the cut surfaces, without necrosis and hemorrhage. Microscopically, the neoplasm was composed of ovoid to spindle-shaped tumor cells, arranged into whorls arrays. Collagen fiber and multinucleated cells were observed in the background, with areas showing clustering. Parts of the tumor were accompanied with hemosiderin. Necrosis and hemorrhage were not observed. Mitotic figures were rare (Ki-67 immunoproliferative index of 10\%; Fig. 1D). A total of 500-2,000 tumor cells were counted manually to evaluate the Ki-67 immunoproliferative index.
The tumor was lightly infiltrated by small lymphocytes with lymphoid follicle formation (Fig. 1A).

IHC revealed that the tumor cells were positive for D2-40 (Fig. 1G), Vimentin,CD21, CD23, CD117, EGFR, ALK and HMB45, and negative for cytokeratin (CK), actin smooth muscle (SMA), Actin, P53, Desmin, MelanA, CD1a and CD34 (Fig. 1D and G).

The diagnosis of FDCS was made based on the morphological and immunological characteristics. In view of its rarity, the patient was suggested to further consult the pathologists of the Department of Pathology of the China-Japan Friendship Hospital, and the diagnosis was determined again. The postoperative recovery of the patient was rapid without complications. During the 5-month post-operative follow-up period, no recurrence, metastasis or other signs of discomfort were observed.

Case 2. A 70-year old male patient checked into the Oncology Department of the Affiliated Hospital of Chengde Medical College, with an abnormal sensation in the throat for 3 months. The patient had no dyscatabrosis, fever or dyspnea. Upon ultrasound examination, a suspicious mass was revealed at the right tonsil. The cervical lymph node was not enlarged. A right tonsillectomy was performed under general anesthesia. Grossly, fragmentary tissue measuring $2 \times 2 \times 0.5 \mathrm{~cm}$ was observed. Microscopically, the biggest part of the tonsil was covered by mature squamous cells, while an ulcer was found on the surface. Under the squamous cells, an ovoid to round-shaped tumor formed solid or nested patterns. Some tumor cells exhibited prolonged nuclei and obvious nucleoli, as well as an eosinophilic cytoplasm. Significant cytological atypia, focal coagulative necrosis and hemorrhage were identified. Lymphocytes, eosinophils and plasmocytes were also observed under light microscopy (Fig. 1B and C). Immunohistochemically, the tumor cells were positive for CD21, epithelial membrane antigen (EMA) and CD35 (Fig. 1E, F and H, respectively), weakly positive for CD68, and negative for CD20, CD3, CD30, S-100, Lyso, CD1a, ALK and leukocyte common antigen (LCA). The patient underwent postoperative radiotherapy as well. During the 4-month follow-up period after undergoing tonsillectomy, no local recurrence or distant metastasis was observed.

\section{Literature review}

Literature review. The literature was reviewed by searching the key words 'extranodal follicular dendritic cell' on PubMed (www.ncbi.nlm.nih.gov/pubmed), and the Chinese literature was searched on the China National Knowledge Infrastructure (http://www.cnki.net/) between 2008 and 2019. All the cases of FDCS, except those in lymph nodes, were collected. As much of the literature as possible was consulted to ensure each case was reported only once and discern the renewed information about the cases.

Statistical analysis. SPSS 17.0 (SPSS, Inc.) was used for statistical analysis. The Life Tables method was used to calculate the overall and tumor-free survival rates. The association between clinicopathological parameters and prognosis were calculated using Kaplan-Meier estimation and the log-rank test. $\mathrm{P}<0.05$ was considered to indicate a statistically significant difference. 
Table I. Antibodies and results of immunostaining.

\begin{tabular}{|c|c|c|c|c|}
\hline \multirow[b]{2}{*}{ Antibodies } & \multirow[b]{2}{*}{ Clone no. } & \multirow[b]{2}{*}{ Catalogue numbers } & \multicolumn{2}{|c|}{ Results } \\
\hline & & & Case 1 & Case 2 \\
\hline CD21 & EP64 & ZA-0525 & $+/-$ & + \\
\hline D2-40 & D2-40 & ZM-0465 & + & / \\
\hline CD23 & OTI2B6 & TA801531 & $+/-$ & l \\
\hline Vimentin & EP21 & ZA-0511 & + & l \\
\hline CD117 & EP10 & ZM-0371 & Partly + & l \\
\hline EGFR & EP22 & ZA-0505 & Partly + & / \\
\hline ALK & OTI1H7 & ZM-0248 & Partly + & - \\
\hline HMB45 & HMB45 & ZM-0187 & Partly + & / \\
\hline Ki-67 & EP5 & ZA-0502 & $10 \%$ & l \\
\hline $\mathrm{CK}$ & AE1/AE3 & ZM-0069 & - & / \\
\hline SMA & UMAB237 & ZM-0003 & - & / \\
\hline Actin & HHF35 & ZM-0001 & - & / \\
\hline P53 & EP9 & ZM-0408 & - & / \\
\hline Desmin & EP15 & ZA-0610 & - & / \\
\hline MelanA & A103 & TA807226 & - & / \\
\hline CD1a & EP80 & ZA-0544 & - & - \\
\hline CD34 & EP88 & ZA-0550 & - & l \\
\hline EMA & UMAB57 & ZM-0095 & l & + \\
\hline CD68 & PG-M1 & ZM-0464 & l & $+/-$ \\
\hline S-100 & 15E2E2+4C4.9 & ZM-0224 & l & - \\
\hline Lyso & l & l & l & - \\
\hline LCA & 2B11\&PD7/26 & ZM-0183 & l & - \\
\hline CD20 & EP7 & ZA-0293 & l & - \\
\hline CD3 & EP4 & ZA-0503 & l & - \\
\hline CD30 & EP154 & ZA-0591 & l & - \\
\hline CD35 & EP197 & ZA-0638 & 1 & + \\
\hline
\end{tabular}

LCA, leukocyte common antigen; HMB45; CK, cytokeratin; SMA, actin smooth muscle; EMA, epithelial membrane antigen); +, positive; -, negative; +/-, weekly positive; /, not applicable. All the antibodies shown in the table were used as working solutions and not diluted. The scoring method based on both the intensity ( 0 , no staining; 1 , weak staining; 2 , medium staining; and 3, strong staining) and proportion of positive cells $(0,0 \% ; 1,1-25 \% ; 2,26-75 \% ; 3,76-100 \%)$. The final staining score was calculated by multiplying the staining intensity score by extent of staining score. A final staining score of $\geq 3$ was considered positive, and others were classified as negative.

Clinical features of extranodal FDCS. A total of 102 cases of extranodal FDCS were retrieved from the literature (Table II) (1-55). The clinicopathological features, management and clinical outcomes were extracted and recorded. Of the 102 cases, 55 were male and 47 female (male to female ratio, 1.17:1) and the age range was $16-79$ years at the time of diagnosis (mean age, 48.87 years; median age, 47.5 years). The tumors were located in different regions, including the abdominal cavity $(n=46)$, tonsil $(n=20)$, oropharynx $(n=15)$, mediastinum $(n=12)$, neck soft tissue $(n=2)$, pelvic cavity $(n=2)$, bone $(n=1)$, lower limbs $(n=1)$, intracranium $(n=1)$, esophagus $(n=1)$ and thyroid $(n=1)$. The tumor longitudinal diameter measured $1-20 \mathrm{~cm}$, with a mean diameter of $6.63 \mathrm{~cm}$, an abdominal cavity diameter of $8.33 \mathrm{~cm}$ and a diameter of the outside of the abdominal cavity of $4.74 \mathrm{~cm}$. A total of 8 cases were coexistent with other diseases, including 1 with Castleman disease, 3 with paraneoplastic pemphigus, 2 with chronic hepatitis B virus infection and 2 with carcinoma.
Pathological features of extranodal FDCS. Most of the cases from the literature were well circumscribed, with grey white-red cutting surfaces. Focal coagulative necrosis $(n=20)$ and hemorrhage $(n=14)$ were observed in some cases. Mitotic figures were rarely observed [range, rare-30/high power field (HPF)]. Generally, extranodal FDCS is positive for specific markers for DCs, such as CD23, D2-40, CD35 and CD21. One case of urinary bladder FDCS was negative for BRAF. EBV-encoded RNA (EBER) was detected using in situ hybridization (ISH) in 53 cases and it was positive in 20 and negative in 23 cases, most located in the liver and spleen. A total of 19 cases were misdiagnosed to other tumors or inflammatory lesions (Table II).

Management and clinical outcomes of extranodal FDCS. The data of the management of the extranodal FDCS cases were available for 95 cases. A total of 50 cases underwent surgery to resect the neoplasm. A total of 1 case received 

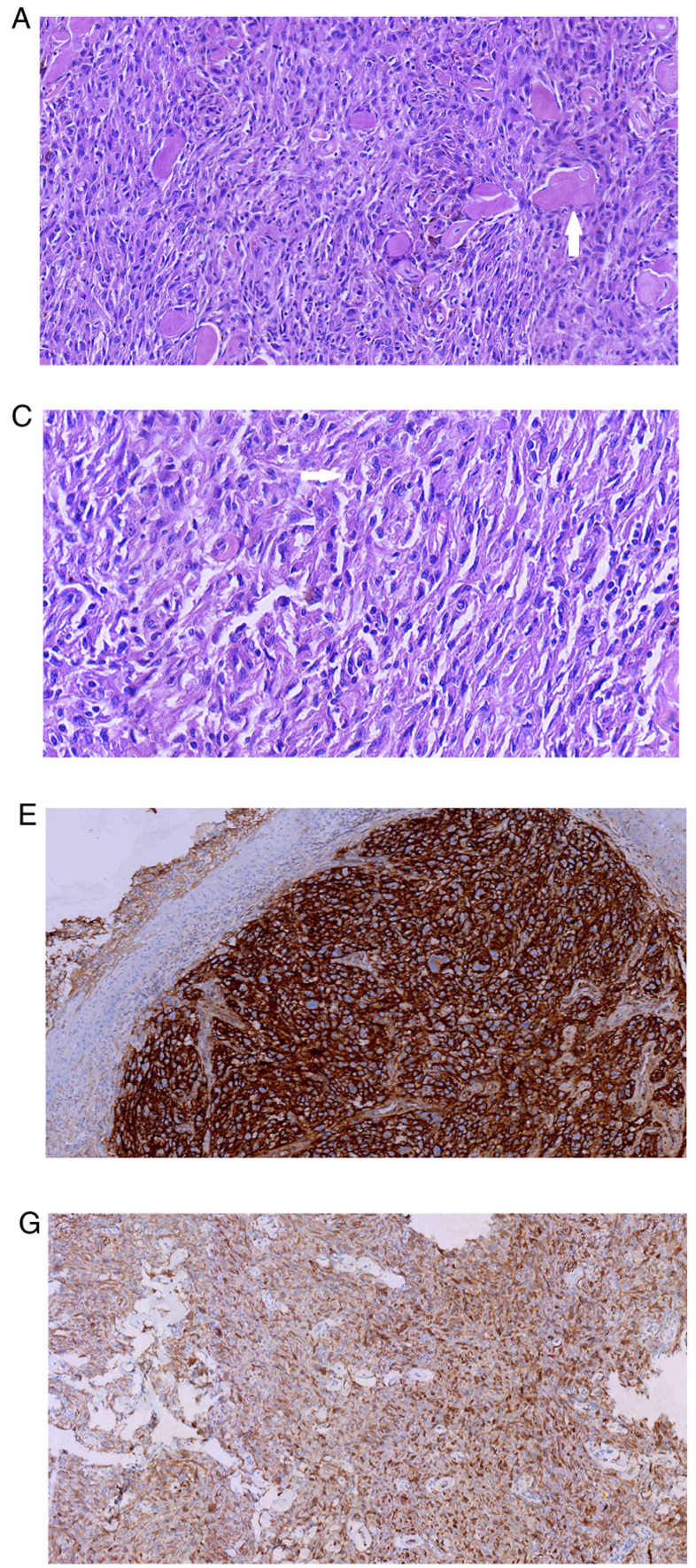
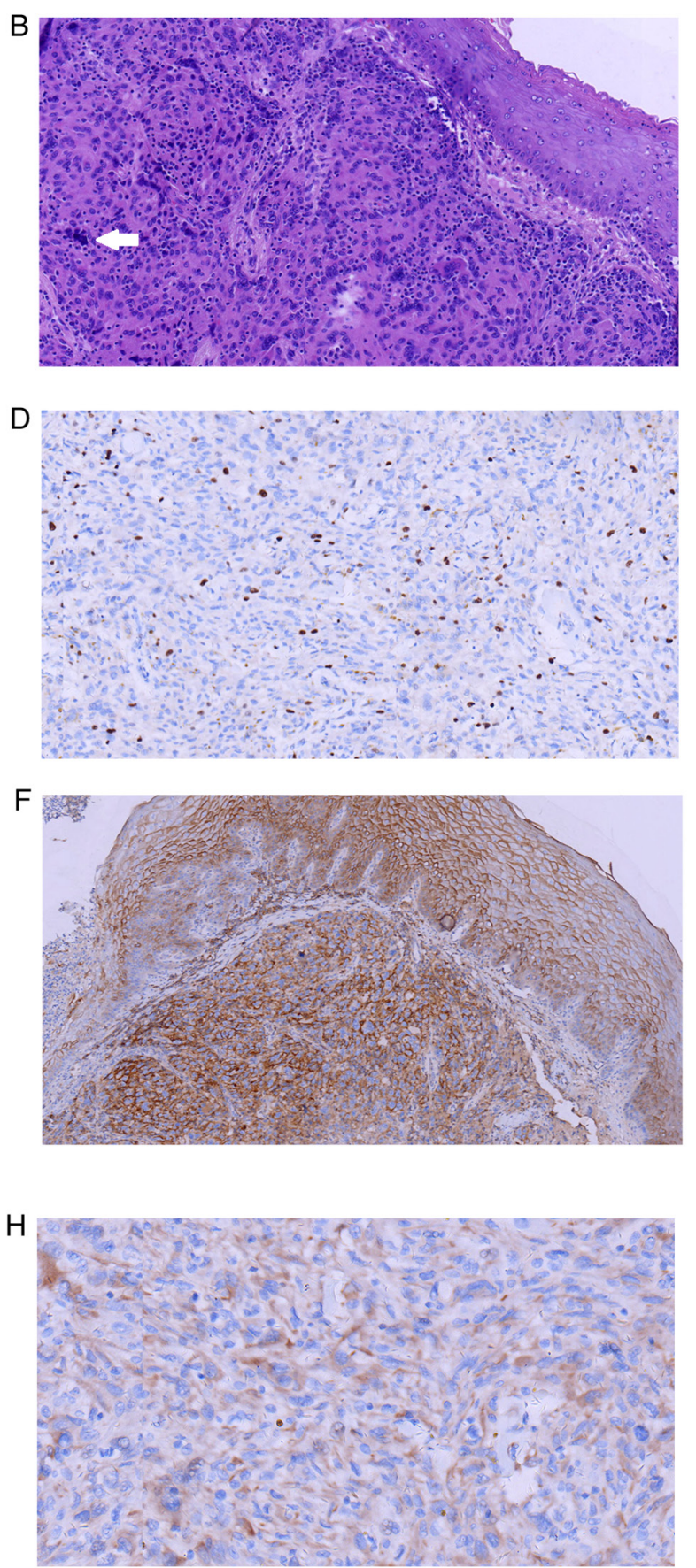

Figure 1. Pathological features of extranodal follicular dendritic cell sarcoma. (A) Neoplasm cells are arranged in a fascicular pattern and storiform structure, with collagen fibers seen in the background (HE; magnification, x20). Arrow denotes collagen fibers seen in the background. (B) Tumor cells under the squamous cells (H\&E; magnification, x20). Arrow denotes significant cytological atypia. (C) The shape of tumor cells was ovoid-round (H\&E; magnification, $\mathrm{x} 40$ ). Arrow denotes ovoid-shape of the tumor cells. (D) Ki-67 expression in case 1 (IHC; magnification, $\mathrm{x} 20$ ). (E) CD21 expression in case 2 (IHC; magnification, x10). (F) EMA expression in case 2 (IHC; magnification, x10). (G) D2-40 expression in case 1 (IHC; magnification, x10). (H) CD35 expression in case 2 (IHC; magnification, $\mathrm{x} 20)$. HE, hematoxylin and eosin; IHC, immunohistochemistry.

chemotherapy procedures, while 44 cases came to the clinic for adjuvant treatment (17 cases for radiation treatment, 16 for chemotherapy and 11 for both). Complete follow-up information was accessible in 82 cases. The follow-up duration was 1-108 months, with an average of $24.31 \pm 22.98$ months (Table II). The 2- and 5-year total survival rates were 70 and $70 \%$, respectively. The 2 - and 5-year tumor-free total survival rates were 68 and $32 \%$, respectively (Table III and Fig. 2). The rates of recurrence, metastasis and mortality were
$14.63(12 / 82), 17.07(14 / 82)$ and $18.29 \%$ (15/82), respectively (Table III). The median survival time was 108 months.

Prognostic factors of extranodal FDCS. The Kaplan-Meier method was used to analyze the association between clinicopathological features and prognosis (Table III and Figs. 3-6). Upon this analysis, it was found that sex was associated with disease-free survival $(\mathrm{P}=0.032$; Table III), with female patients having a poorer prognosis than male patients. 


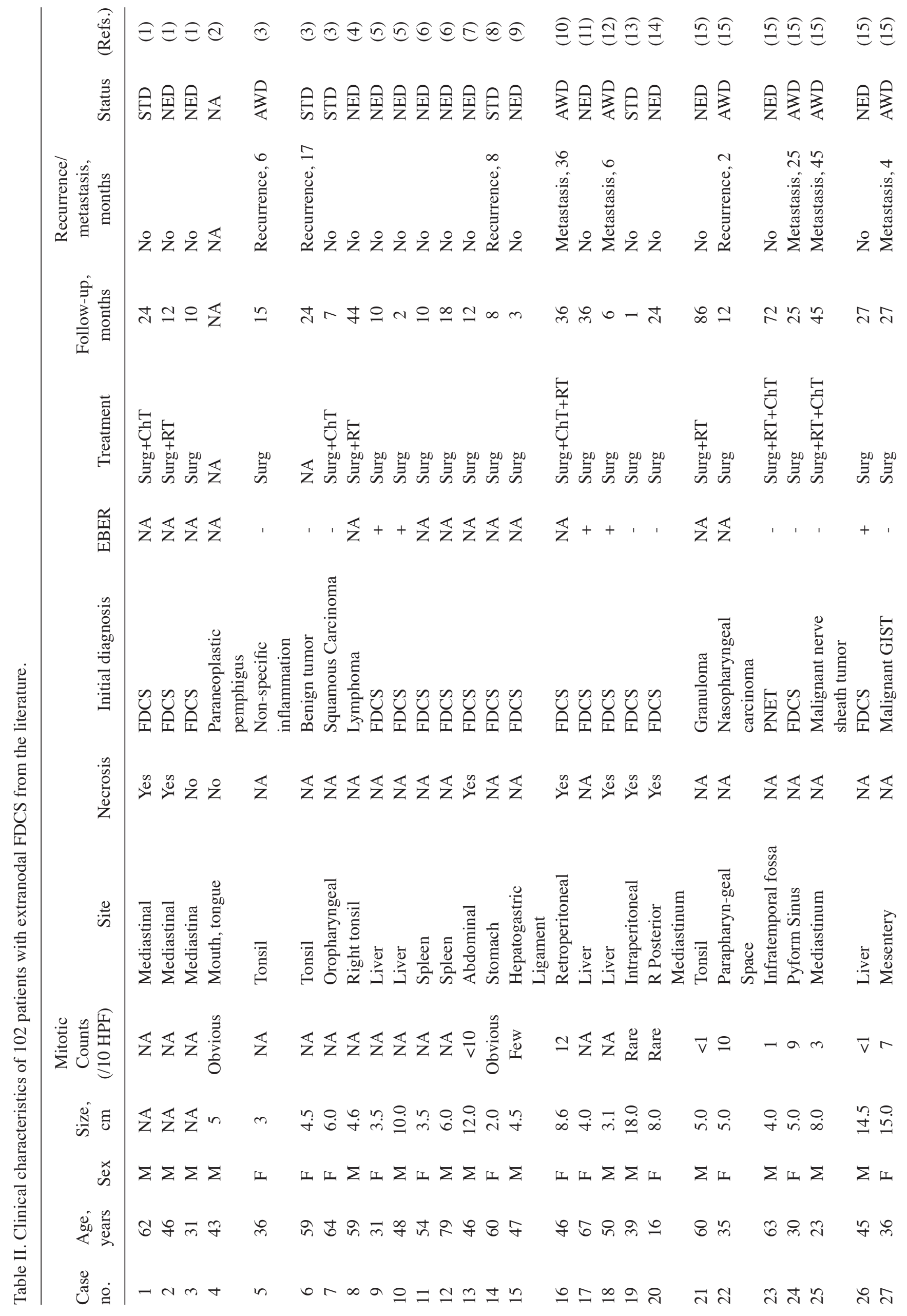




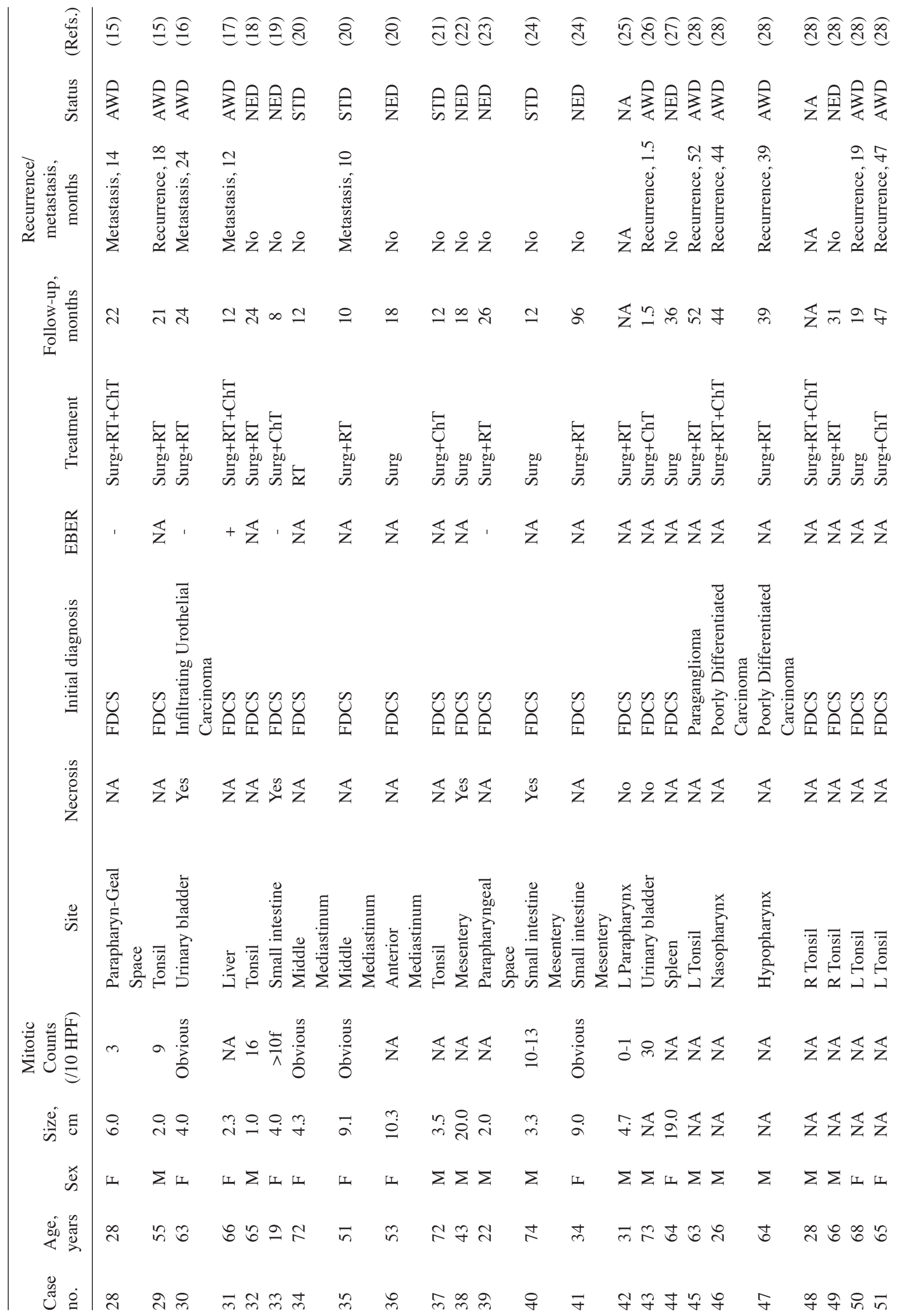




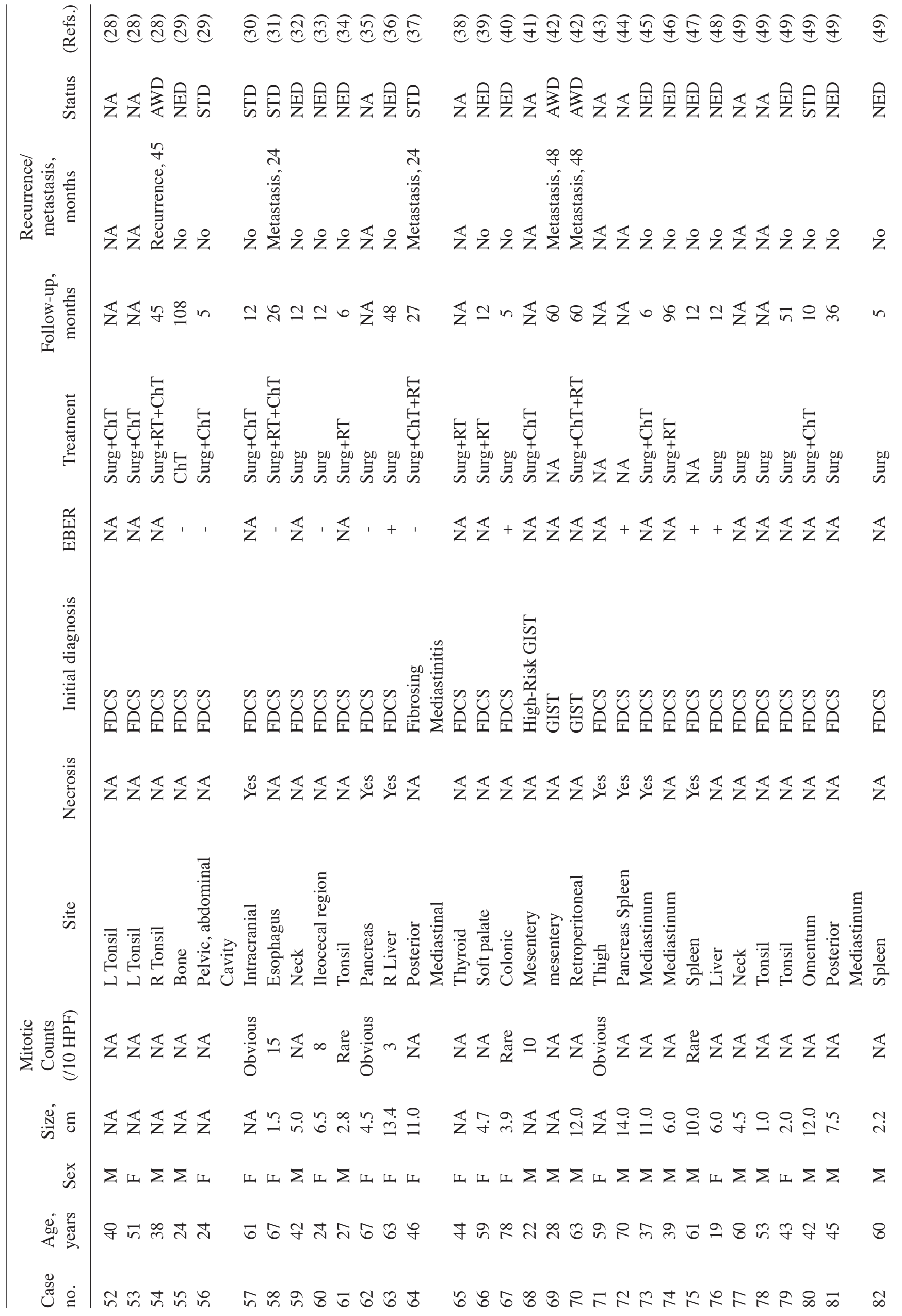




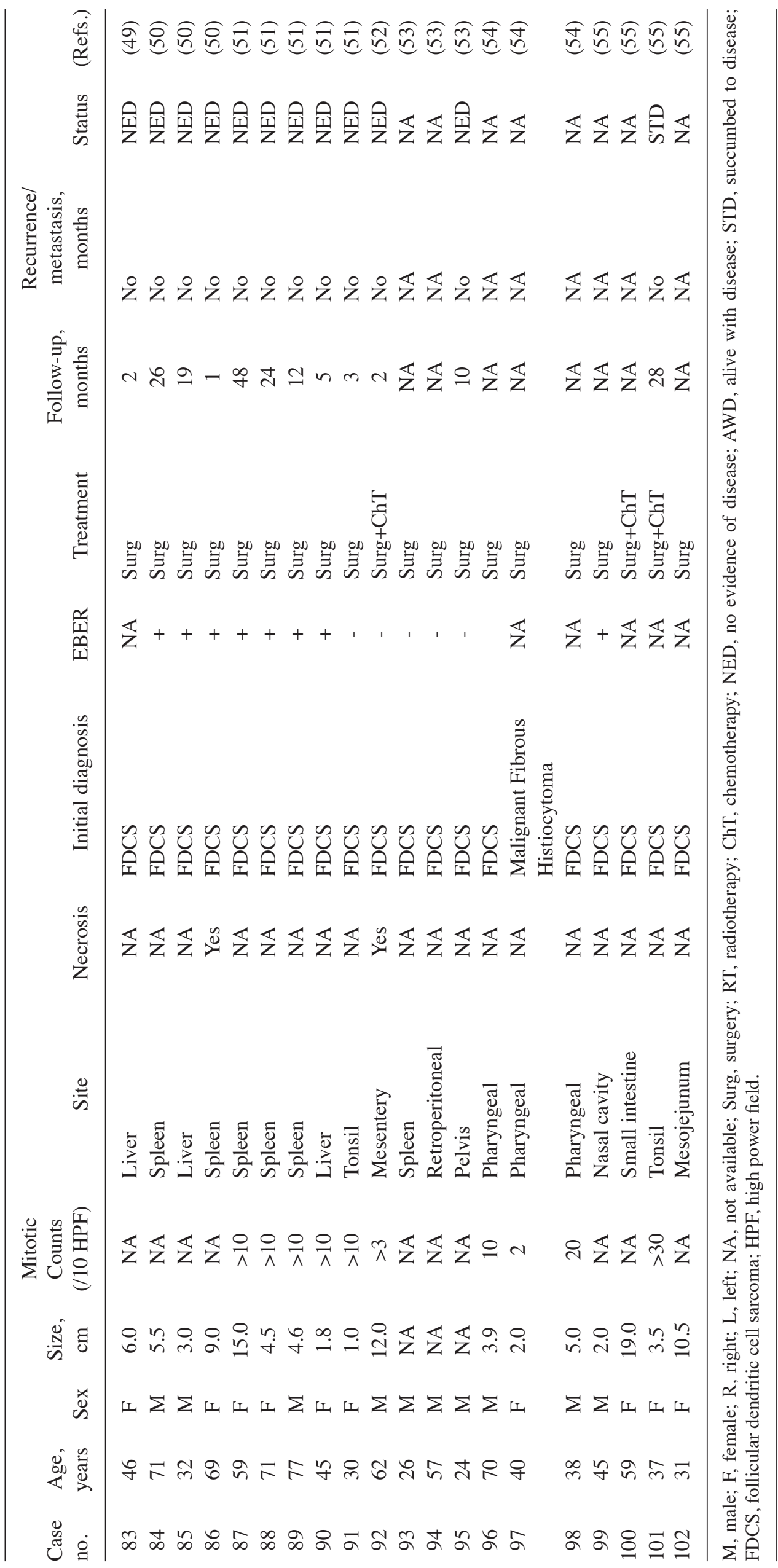




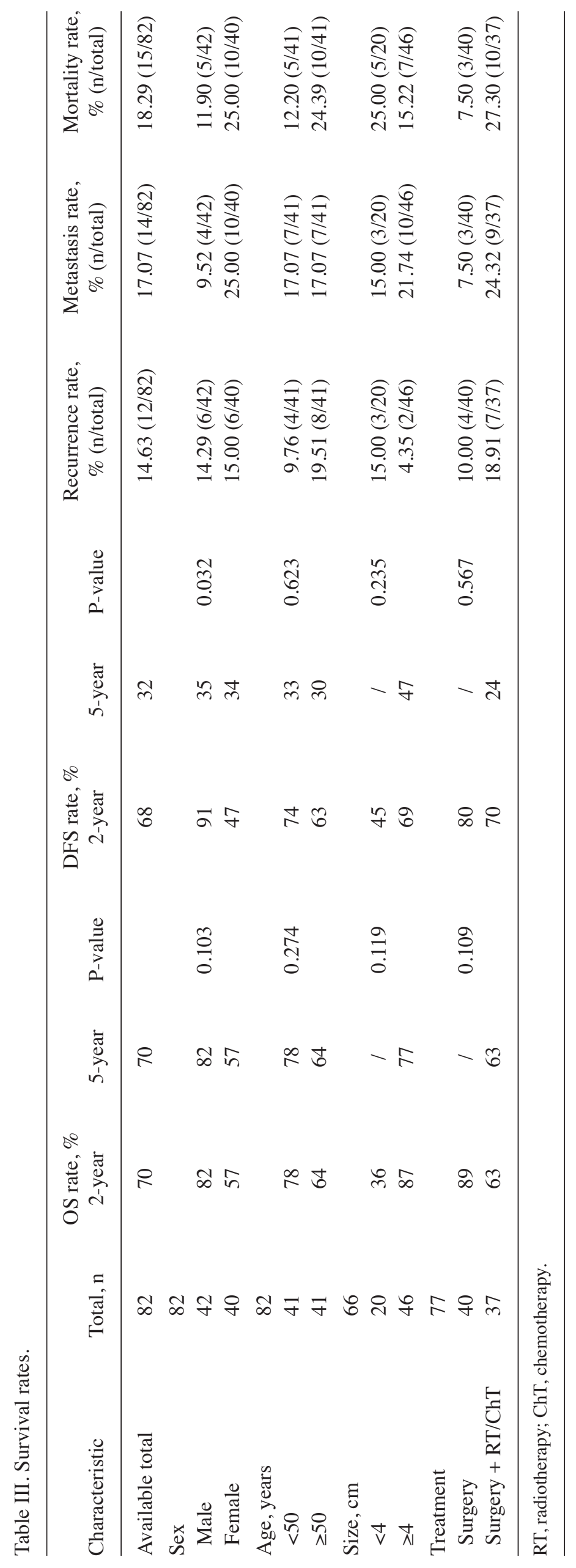


A

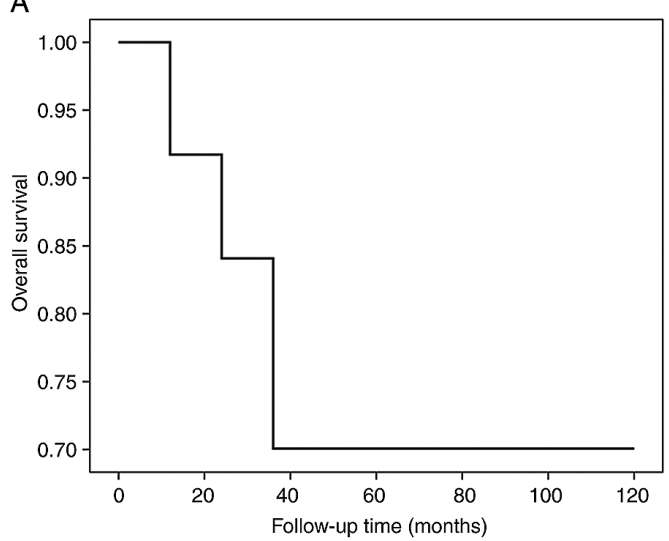

B

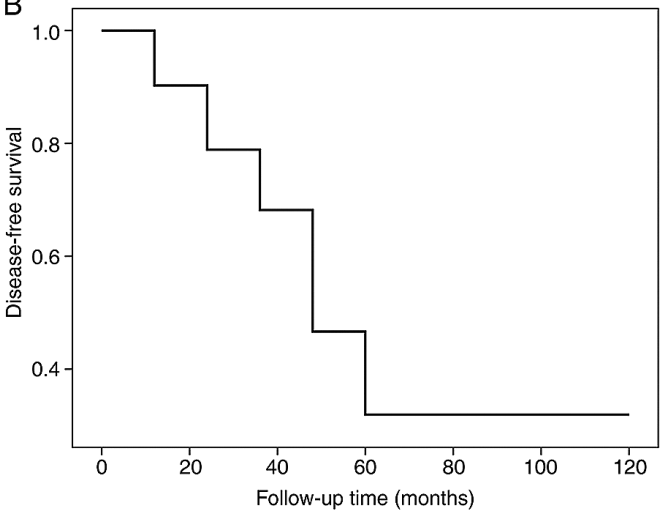

Figure 2. Survival curves of extranodal follicular dendritic cell sarcoma. (A) Overall survival and (B) disease-free survival curves.
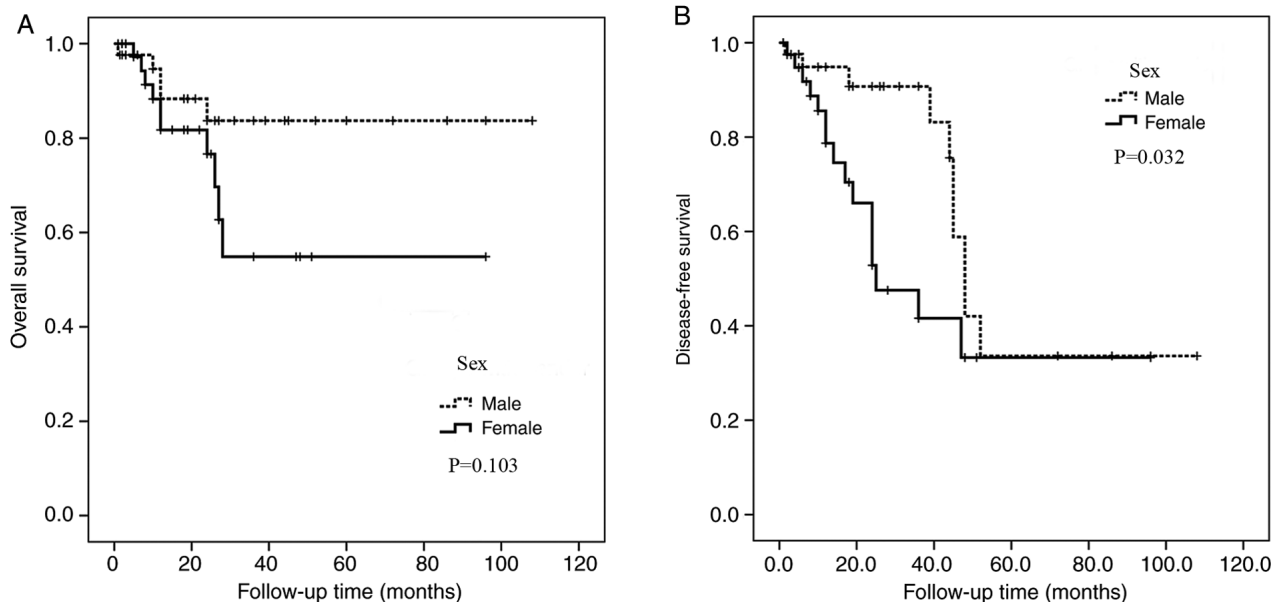

Figure 3. Survival curves of extranodal FDCS. (A) Overall survival and (B) disease-free survival curves of patients with FDCS according to sex. FDCS, follicular dendritic cell sarcoma.
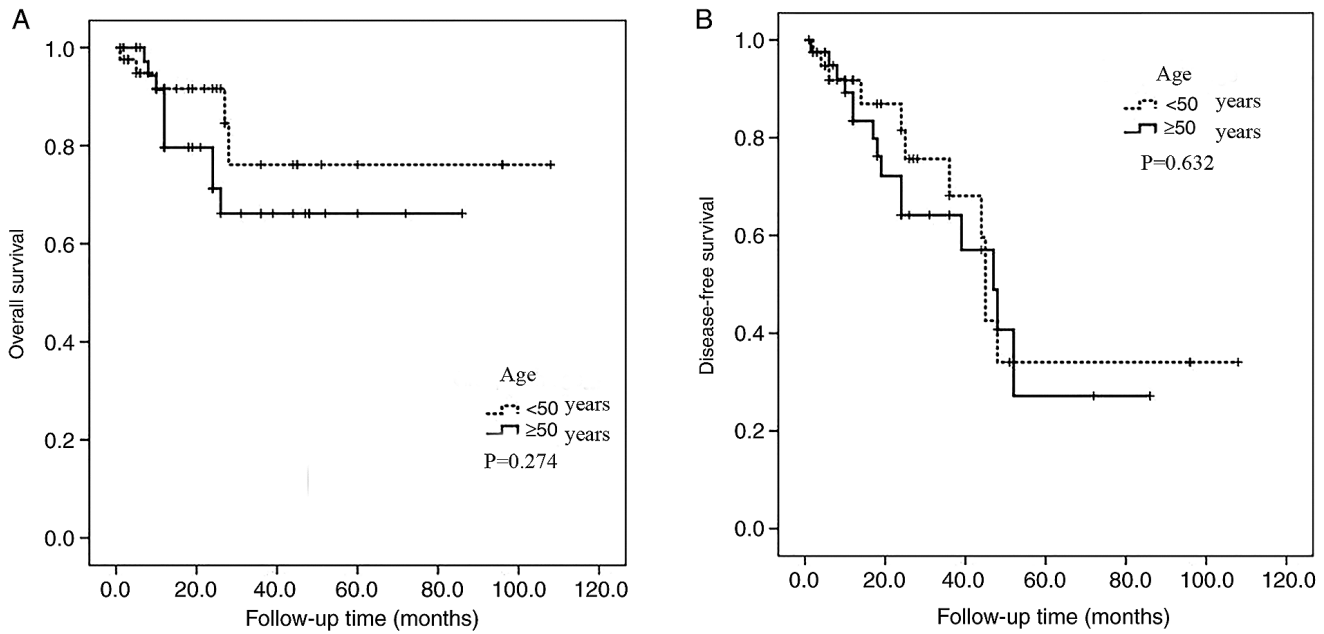

Figure 4. Survival curves of extranodal FDCS. (A) Overall survival and (B) disease-free survival curves of patients with FDCS according to age. FDCS, follicular dendritic cell sarcoma.

Kaplan-Meier estimation exhibited no other statistically significant differences between disease-free survival rates or overall survival rates and age, tumor size or treatment (Table III).

\section{Discussion}

FDCS is an extremely rare tumor that affects the lymphoid tissues and mostly presents in the lymph nodes, while the 

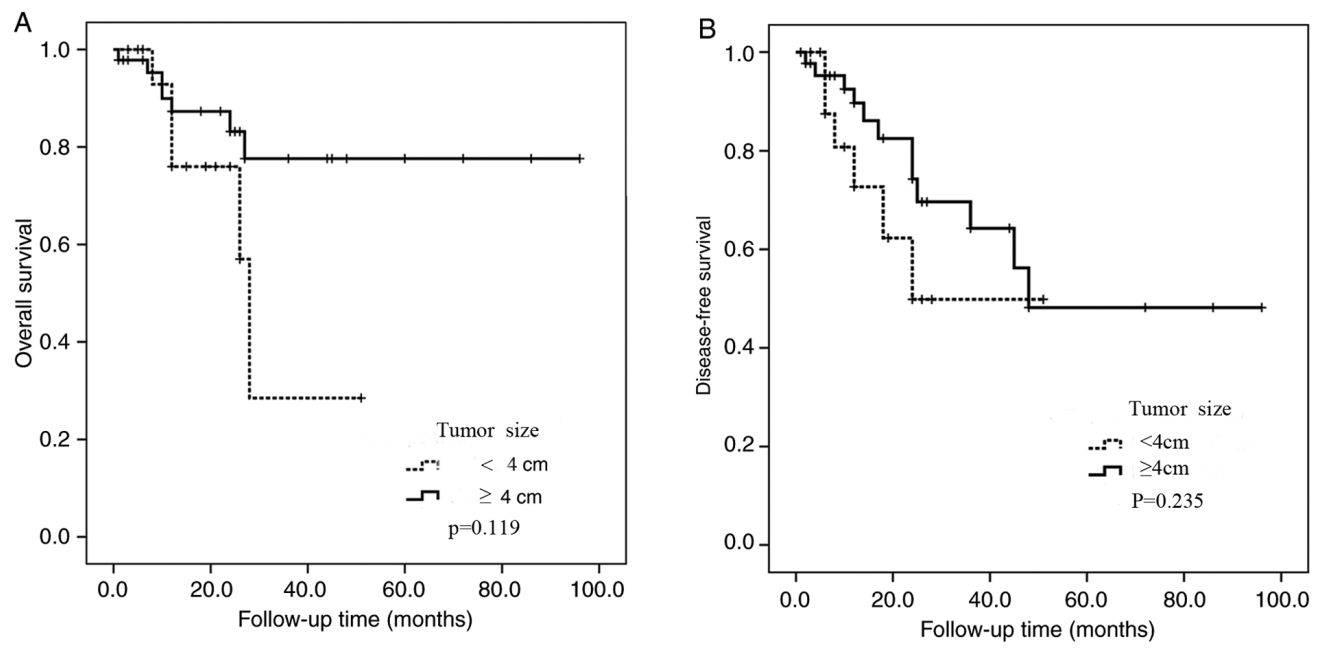

Figure 5. Survival curves of extranodal FDCS. (A) Overall survival and (B) disease-free survival curves of patients with FDCS according to tumor size. FDCS, follicular dendritic cell sarcoma.
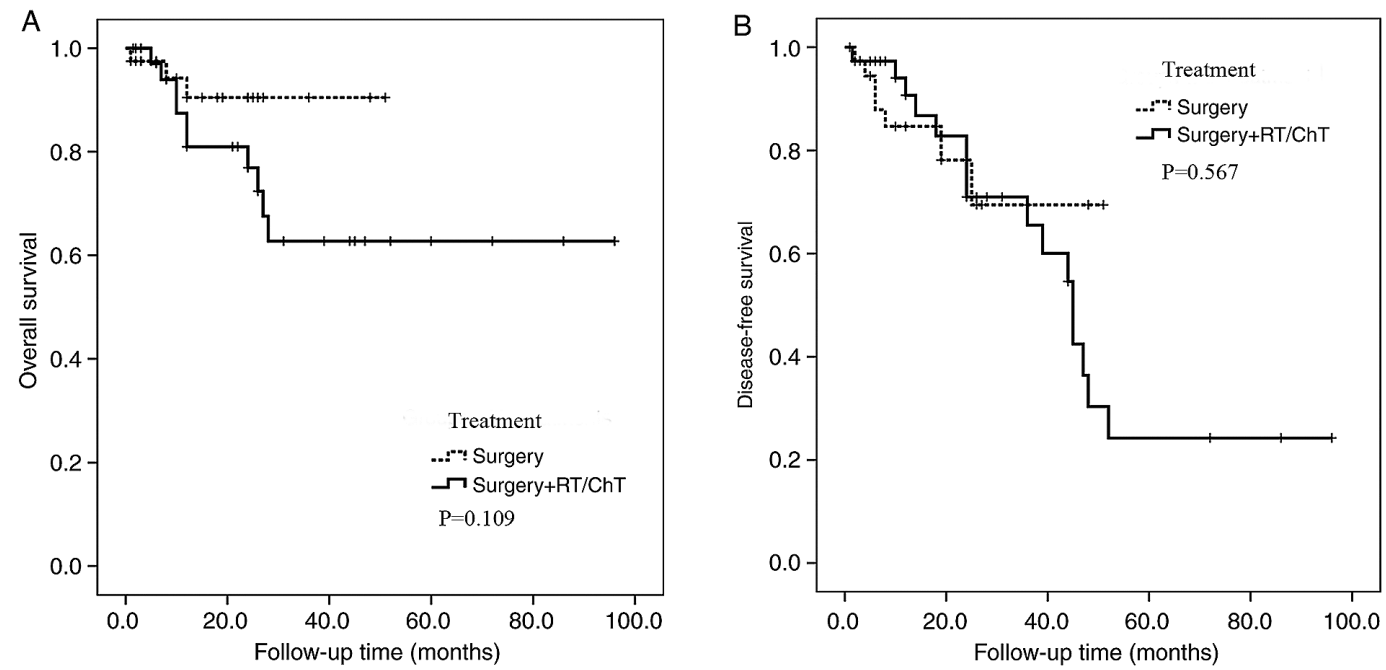

Figure 6. Survival curves of extranodal FDCS. (A) Overall survival and (B) disease-free survival curves of patients with FDCS according to treatment. RT, radiotherapy; ChT, chemotherapy; FDCS, follicular dendritic cell sarcoma.

extranodal type of the disease accounts for only one-third of cases (5). Due to the limited number of reported cases, a proportion of FDCSs, particularly extranodal FDCSs, has been difficult to recognize, especially on purely morphological grounds (11). FDCS has been proven to derive from DCs or macrophages, making it similar to diffuse large B-cell lymphoma or anaplastic large cell lymphoma, and therefore complicating its diagnosis $(6,9)$. Additionally, the diagnosis of extranodal FDCS is even more challenging $(2,5,10)$. Currently, to the best of our knowledge, the clinical manifestations and prognosis-associated factors of extranodal FDCS have not been statistically described. The present study presented two cases of extranodal FDCS affecting the tonsil and soft tissue of the chest wall, respectively. Additionally, 102 cases of extranodal FDCS from the literature were analyzed (1-55).

The existence of FDC tumors (FDCTs) was first described by Lennert in 1978 (56), but it was Monda et al (57) who in 1986 recognized and characterized this type of tumor. As antigen-presenting cells, DCs can be found in various sites and participate in multiple types of activations $(20,22)$. Langerhans cells are specialized dendritic cells in mucosal sites and skin that upon activation become specialized for antigen presentation to $T$ cells, and then migrate to the lymph node through lymphatics $(14,15)$. In contrast to other types of myeloid-derived DCs (such as Langerhans cells, interdigitating DCs and dermal/interstitial DCs), FDCs seem to stem from bone marrow stromal cells, with myofibroblasts as a characteristic $(35,42)$. FDCs are located in primary and secondary follicles, trapping and presenting antigens to B cells, and storing immune complexes for long periods of time on the cell surface $(58,59)$. The cause of FDCT remains unknown; potential risk factors may be Epstein Barr Virus (EBV) infection or Castleman disease $(2,26)$, which may be found concurrently with FDCS or may precede the latter by several years (27). EBV is suspected to carry a viral oncogene-latent membrane protein 1 that may encourage transformation, often detected in the spleen and liver $(30,34)$. 
Among the 102 cases from the literature, EBER was positive mostly in the liver and spleen, except for one case in the colon. A number of cases appeared to be associated with autoimmune diseases, such as paraneoplastic pemphigus and myasthenia gravis. It has been suggested that FDCS encourages aberrant immune system activation, given that patients often demonstrate immature T cells $(8,15)$.

The epidemiology of FDCS is unclear. A wide age range has been reported, but FDCS was most common in adults (50). Similarly, the mean age of the patients in the present study was 48.87 years (range, 16-79 years), and the median age was 47.5 at initial presentation. The sex distribution was similar, and the overall male to female ratio was $1.17: 1$. In the present study, FDCS was slightly more common in males, which was inconsistent with the results of Shaw et al (8). The mean diameter of the tumors was $6.63 \mathrm{~cm}$ (range, $1-20 \mathrm{~cm}$ ). Tumor size was closely associated with the primary site and was larger in the inner abdomen compared with in other sites. Most FDCS present as lymphadenopathy, but a number of extranodal regions, such as the soft tissue, tonsil, stomach and intestines, were found to be the primary sites. Systemic symptoms were uncommon. Sometimes patients complained of a slow-growing, painless lump, while others visited the doctor presenting with abdominal pain, which was usually due to an abdominal tumor; rarely patients had paraneoplastic pemphigus (such as 2 cases in the present literature review).

The gross observation and histopathology are manifold. Overall, the cut surface of most extranodal FDCS had a yellowish white appearance, was circumscribed and caused extrinsic compression in some cases. Microscopically, the neoplastic cells were arranged in a fascicular pattern and had a storiform structure, with an ovoid-round shape. Similar to meningioma, a whorl pattern was observed in certain areas. At high power, tumor cells with a slightly eosinophilic cytoplasm, distinct elongated nuclei and cell membrane were observed. Lymphocytes were dispersed characteristically in the background. The mitotic rate was $0-10 / \mathrm{HPF}$, with a higher rate of $>30 / \mathrm{HPF}$ in pleomorphic cases, with easily seen coagulative necrosis and pathological karyokinesis. FDCS is classified into two types, the classic FDCS and inflammatory pseudotumor (IPT)-like FDCS $(35,48)$. IPT-like FDCS is rarer than the classic type and typically presents as a renal and hepatic lump $(35,51)$. Histologically, lymphoplasmacytic spindle cells infiltrate the tumor, mainly including plasma cells, lymphocytes and a small number of neutrophils, sometimes with a lymphoid follicle formation (51). In the 2 cases of the present study, tumor cells were ovoid-to-spindle-shaped, forming solid or nested patterns or whorls arrays. The tumor was lightly infiltrated by small lymphocytes and multinucleate cells. IHC and ISH are essential for the diagnose of FDCS. No single marker is able to identify all DC subsets; as described in the WHO classification $(58,60)$, important markers include D2-40, CD23, CD21 and CD35 (3). In the two cases of the present study, the tumor cells were both positive for CD21.

The diagnosis of extranodal FDCS depends mainly on pathology; therefore, due to its infrequency and non-specific histopathological features, misdiagnosis occurs frequently. The most common reason for misdiagnosis is failure to consider FDCS at the initial pathological evaluation. By reviewing the aforementioned literature, it was found that some cases were misdiagnosed as non-specific inflammation, benign tumor, carcinoma, lymphoma, granuloma, pancreatic neuroendocrine tumour and gastrointestinal stromal tumour (GIST). In the study by $\mathrm{Hu}$ et al (3), the misdiagnosis rate was $57 \%$, higher than that in the present study. Carcinoma and FDCS cells are all ovoid cells with avesicular nuclei; however, carcinomas are positive for CK and negative for CD21, CD23 and CD35 (21,53). Similarly to FDCS, GISTs exhibit fascicles, storiform arrays and whorls patterns, and are negative for $\mathrm{CK}$, but immune histochemical markers are positive for Dog-1, CD34 and CD117, and negative for specific markers for FDCS, which may be used to distinguish GIST from FDCS $(5,19)$.

The limited cytogenetic data exhibit complex karyotypes. A targeted next-generation sequencing study indicated frequent function loss alterations in tumor suppressor genes, negative regulation of $\mathrm{NF}-\kappa \mathrm{B}$ and cell-cycle progression involvement (60).

The use of the genomic sequencing approach enhanced the understanding of genomic features of FDCS in the thyroid (38). Extensive mutations were detected, including VEGFR1, CLTCL1 and TP53 mutations and hepatoma-derived growth factor related protein 3 (HDGFRP3) and Src homology 2 domain containing family member 4 (SHC4) $(10,19)$. SHC4 is associated with the EGFR signaling pathway, from which it was deduced that this pathway may serve a role in the etiopathogenesis of FDCS (25). The BRAF V600E mutation was also reported in $0-19 \%$ of cases $(61,62)$.

The treatment of FDCS has not been standardized, as there is no worldwide consensus due to the rarity of the reported cases and limited prospective research on prognosis. The shortage of medical molecular genetics hindered the development of targeted treatments. In most cases, patients with FDCS receive surgery and adjuvant radiotherapy or chemotherapy $(33,52)$. Radical dissection is an important treatment of regional lumps, particularly tumors appearing to have clear boarders (63). Postoperative radiotherapy is recommended, with total doses of 6,000-7,000 cGy in the head and neck region $(3,8)$. With regards to chemotherapy, the options targeting non-Hodgkin's lymphoma are most commonly used (64). However, it remains controversial whether it is beneficial to administer radiotherapy or chemotherapy post-surgically. In the present study, only 50 cases underwent surgery, and combination therapy was administered post-operatively to 45 cases; however, a comparison of prognosis between the surgery only and the adjuvant treatment groups did not yield any significant results $(\mathrm{P}>0.05)$.

FDCS is a type of low-intermediate grade malignant tumor. Due to a shortage of cases, the prognosis and predictive factors are not definite. Saygin et al (65) reported 2-year survival rates for early stage, local infiltration and distant metastasis stage of 82,80 and $42 \%$, respectively. By reviewing the data of 42 FDCS cases in the tonsils, Lu et al (4) revealed that the 3 -year overall survival rate was $86.5 \%$, a little higher than the 5- and 8-year rates (both 77.8\%). By reviewing 32 subjects of mediastinal FDCS, Wu et al (1) identified that the 1-year total and tumor-free survival rates were 80.4 and $76.9 \%$, respectively, the 3-year total and tumor-free survival rates were 68.5 and $51.7 \%$, respectively, and the 5-year rates were 58.8 and $32.3 \%$, respectively.

According to the investigation of WHO, prognostic analysis of extranodal FDCS is scarce. In the present 
study, the follow-up duration was 1-108 months, with an average of $24.31 \pm 22.98$ months, and the 2- and 5-year total survival rates were both $70 \%$. The 2- and 5-year disease-free total survival rates were 68 and $32 \%$, respectively. Domínguez-Malagón et al (66) demonstrated that FDCS originating from the pharyngeal region had low recurrence $(25 \%)$, metastasis $(25 \%)$ and mortality rates $(5 \%)$, similar to those of Duan et al (67) $(23,21$ and 3\%, respectively). In the present study, the rates of recurrence, metastasis and mortality were 14.63 (12/82), 17.07 (14/82) and 18.29\% (15/82), respectively. These different results may be due to the limitation of the tumor sites. FDCS in the parapharyngeal space exhibited poorer outcomes, while intra-abdominal tumors are more likely to recur $(40,42)$. However, in the present study, the follow-up data available for analysis were scarce, the follow-up time was short and the survival curves were founded on a small number of cases, affecting the availability and effectiveness of the present study. The prognostic factors of extranodal FDCS remain unclear, and may include tumor diameter, necrosis and mitotic count (65). Lu et al (4) reported that a large tumor size resulted in a poor prognosis, and $\mathrm{Hu}$ et al (3) detected that combined treatment improved survival rates. The current study revealed that sex was a significant prognostic factor. However, Kaplan-Meier estimation exhibited no other statistically significant differences between disease-free survival rates or overall survival rates and age, tumor size or treatment. Due to the scarcity of the follow-up data available for analysis, the current data are insufficient, and more data and further analyses are urgently required.

In conclusion, two rare cases of primary extranodal FDCS were presented, and 102 cases from the literature were reviewed. The present study described the known biological behavior of extranodal FDCS. The confirmation of pathology of extranodal FDCS is challenging, leading to further delays in diagnosis. Surgical resection remains essential for definitive treatment. Further research into the pathogenesis and therapy of FDCS is required to improve the outcomes of this rare disease.

\section{Acknowledgements}

Not applicable.

\section{Funding}

The present study was supported by Baoding Science and Technology Project (grant no. 18ZF097).

\section{Availability of data and materials}

The datasets used and/or analyzed during the present study are available from the corresponding author upon reasonable request.

\section{Authors' contributions}

$\mathrm{XZ}$ collected and analyzed the data, GZ made substantial contributions to the acquisition of data, analysis and interpretation of data and DS made substantial contributions to conception and design. All authors wrote the manuscript. All authors have read and approved the final manuscript.

\section{Ethics approval and consent to participate}

The study was approved by the Ethics Committee of the Affiliated Hospital of Chengde Medical College (Chengde, China; approval no. LL049). Written informed consent was obtained from the patients for the storage of samples and data, follow-up contact, and further use of samples and data for research purposes.

\section{Patient consent for publication}

Not applicable.

\section{Competing interests}

The authors declare that they have no competing interests.

\section{References}

1. Wu YL, Wu F, Xu CP, Chen GL, Zhang Y, Chen W, Yan XC and Duan GJ: Mediastinal follicular dendritic cell sarcoma: A rare, potentially under-recognized, and often misdiagnosed disease. Diagn Pathol 14: 5, 2019.

2. Su Z, Liu G, Liu J, Fang T, Zeng Y, Zhang H, Yang S, Wang Y, Zhang J, Wei J, et al: Paraneoplastic pemphigus associated with follicular dendritic cell sarcoma: Report of a case and review of literature. Int J Clin Exp Pathol 8: 11983-11994, 2015.

3. Hu T, Wang X, Yu C, Yan J, Zhang X, Li L, Li X, Zhang L, Wu J, Ma W, et al: Follicular dendritic cell sarcoma of the pharyngeal region. Oncol Lett 5: 1467-1476, 2013.

4. Lu ZJ, Li J, Zhou SH, Dai LB, Yan SX, Wu TT and Bao YY: Follicular dendritic cell sarcoma of the right tonsil: A case report and literature review. Oncol Lett 9: 575-582, 2015.

5. Zhang BX, Chen ZH, Liu Y, Zeng YJ and Li YC: Inflammatory pseudotumor-like follicular dendritic cell sarcoma: A brief report of two cases. World J Gastrointest Oncol 11: 1231-1239, 2019.

6. Ge R, Liu C, Yin X, Chen J, Zhou X, Huang C, Yu W and Shen X: Clinicopathologic characteristics of inflammatory pseudotumor-like follicular dendritic cell sarcoma. Int J Clin Exp Pathol 7: 2421-2429, 2014

7. Testori A, Meroni S, Colombo P, Fiori S, Voulaz E and Alloisio M: Follicular dendritic cell sarcoma with atypical features surrounding undescended testis: Description of a rare case. World J Surg Oncol 13: 69, 2015.

8. Shaw D, Cuison R and Ito H: Follicular dendritic cell sarcoma of the stomach: Case report and review of the literature. Curr Oncol 21: e775-e778, 2014.

9. Yan WX, Yu YX, Zhang P, Liu XK and Li Y: Follicular dendritic cell sarcoma detected in hepatogastric ligament: A case report and review of the literature. World J Clin Cases 7: 116-121, 2019.

10. Yuan T, Yang Q, Zhang H, Li J and Zhang X: A 46-year-old Chinese woman presenting with retroperitoneal follicular dendritic cell sarcoma: A case report. J Med Case Rep 8: 113, 2014.

11. Deng S and Gao J: Inflammatory pseudotumor-like follicular dendritic cell sarcoma: A rare presentation of a hepatic mass. Int J Clin Exp Pathol 12: 3149-3155, 2019.

12. Chin KM, Ho WY, Lim KHT, Chung YFA and Lee SY: Follicular dendritic cell sarcoma of the liver with metachronous small bowel and splenic metastases: A case report and literature review. Hepatobiliary Surg Nutr 6: 179-189, 2017.

13. Akel R, Fakhri G, Salem R, Boulos F, Habib K and Tfayli A: Paraneoplastic pemphigus as a first manifestation of an intra-abdominal follicular dendritic cell sarcoma: Rare case and review of the literature. Case Rep Oncol 11: 353-359, 2018.

14. Miyoshi R, Sonobe M, Miyamoto E and Date H: Completely resected follicular dendritic cell sarcoma of the posterior mediastinum: A report of a case. Surg Case Rep 2: 28, 2016.

15. Li L, Shi YH, Guo ZJ, Qiu T, Guo L, Yang HY, Zhang X, Zhao XM and Su Q: Clinicopathological features and prognosis assessment of extranodal follicular dendritic cell sarcoma. World J Gastroenterol 16: 2504-2519, 2010. 
16. Duan GJ, Wu YL, Sun H, Lang L, Chen ZW and Yan XC: Primary follicular dendritic cell sarcoma of the urinary bladder: The first case report and potential diagnostic pitfalls. Diagn Pathol 12: 35, 2017.

17. Chen HM, Shen YL and Liu M: Primary hepatic follicular dendritic cell sarcoma: A case report. World J Clin Cases 7: 785-791, 2019.

18. Eun YG, Kim SW and Kwon KH: Follicular dendritic cell sarcoma of the tonsil. Yonsei Med J 51: 602-604, 2010.

19. Chang YC, Chau IY, Yeh YC and Chau GY: Small intestine follicular dendritic cell sarcoma with liver metastasis: A case report. Medicine (Baltimore) 96: e7261, 2017

20. Hu J, Dong D, Jiang Z and Hu H: Clinicopathological characteristics of mediastinal follicular dendritic cell sarcoma: Report of three cases. J Cardiothorac Surg 11: 56, 2016.

21. Kara T, Serinsoz E, Arpaci RB and Vayisoglu Y: Follicular dendritic cell sarcoma of the tonsil. BMJ Case Rep 2013: bcr2012007440, 2013

22. Li Z, Jin K, Yu X, Teng X, Zhou H, Wang Y, Teng L and Cao F: Extranodal follicular dendritic cell sarcoma in mesentery: A case report. Oncol Lett 2: 649-652, 2011.

23. Al-Hussain T, Saleem M, Velagapudi SB and Dababo MA Follicular dendritic cell sarcoma of parapharyngeal space: A Case report and review of the literature. Head Neck Pathol 9: $135-139,2015$

24. Xin Z and Kong D: Clinicopathologic profile of extranodal follicular dendritic cell sarcoma in the mesentery of small intestine: A study of two cases with literature review. Int J Clin Exp Pathol 11: 2372-2376, 2018.

25. Pyo JS, Kang G, Do SI, Chae SW, Kim K, Lee SH, Choi YL, Choi JH, Sohn JH and Kim DH: Extranodal follicular dendritic cell sarcoma with rapid growth in parapharynx: A case report. Korean J Pathol 46: 306-310, 2012.

26. Sun J, Wang C, Wang D, Wu J, Wang L, Zhao L and Teng L: Follicular dendritic cell sarcoma (FDCS) of urinary bladder with coexisting urothelial carcinoma-a case report. BMC Urol 19: 83, 2019.

27. Wang L, Xu D, Qiao Z, Shen L, Dai H and Ji Y: Follicular dendritic cell sarcoma of the spleen: A case report and review of the literature. Oncol Lett 12: 2062-2064, 2016.

28. Amirtham U, Manohar V, Kamath MP, Srinivasamurthy PC, Chennagiriyappa LK, Shenoy AM, Renuka PK and Kumar RV: Clinicopathological Profile and outcomes of follicular dendritic cell sarcoma of the head and neck Region-A study of 10 cases with literature review. J Clin Diagn Res 10: XC08-XC11, 2016.

29. Ma Y, Sun J, Yang C, Yuan D and Liu J: Follicular dendritic cell sarcoma: Two rare cases and a brief review of the literature. Onco Targets Ther 8: 1823-1830, 2015.

30. Haranhalli N, Ammar AE, Weidenheim KM, Rosenblum MK and Altschul DJ: Hemorrhagic intracranial follicular dendritic cell sarcoma: A case report. Surg Neurol Int 8: 248, 2017.

31. Ren W, Sun Q, Wu PY, Huang B, Yang J, Yan J and Liu BR Profiles of genomic alterations in primary esophageal follicular dendritic cell sarcoma: A case report. Medicine (Baltimore) 97: e13413, 2018

32. Chidananda-Murthy G, Babu P, Chandran J and Raja G: Unusual presentation of follicular dendritic cell sarcoma as a cystic Neck Swelling. Case Rep Oncol Med 2018: 4038250, 2018.

33. Sarkar R, Sharma S, Roy N, Shankar A and Basu S: Follicular dendritic cell sarcoma of Ileoceacal Region in a young woman: A rare case report with review of literature. Oman Med J 28: e055, 2013.

34. Mondal SK, Bera H, Bhattacharya B and Dewan K: Follicular dendritic cell sarcoma of the tonsil. Natl J Maxillofac Surg 3: 62-64, 2012.

35. Liang W, He W and Li Z: Extranodal follicular dendritic cell sarcoma originating in the pancreas: A case report. Medicine (Baltimore) 95: e3377. 2016.

36. Ang WW, Bundele MM and Shelat VG: Follicular dendritic cell sarcoma: Rare presentation of incidental large hepatic mass. Ann Hepatobiliary Pancreat Surg 23: 74-76, 2019.

37. Cingam SR, Al Shaarani M, Takalkar A and Peddi P: Follicular dendritic sarcoma masquerading as fibrosing mediastinitis. BMJ Case Rep 2017: bcr2016218889, 2017.

38. Davila JI, Starr JS, Attia S, Wang C, Knudson RA, Necela BM, Sarangi V, Sun Z, Ren Y, Casler JD, et al: Comprehensive genomic profiling of a rare thyroid follicular dendritic cell sarcoma. Rare Tumors 9: 6834, 2017

39. Wang L, Cheng H, Li J, Bian D, Chen O, Jin C and Zhao M: Extranodal follicular dendritic cell sarcoma of the soft palate: A case report. Int J Clin Exp Pathol 7: 8962-8966, 2014.
40. Pan ST, Cheng CY, Lee NS, Liang PI and Chuang SS: Follicular dendritic cell sarcoma of the inflammatory pseudotumor-like variant presenting as a colonic polyp. Korean J Pathol 48: 140-145, 2014

41. Pai VD, Desai S, Desouza A and Saklani AP: Extranodal follicular dendritic cell sarcoma: A frequently misdiagnosed entity J Postgrad Med 61: 55-56, 2015.

42. Gupta AM, Goel M, Sahay A, Janjal SP and Patkar S: Role of adjuvant chemotherapy in extranodal follicular dendritic cell sarcoma. ACG Case Rep J 6: 1-4, 2019.

43. Xie Q, Chen L, Fu K, Harter J, Young KH, Sunkara J, Novak D, Villanueva-Siles E and Ratech H: Podoplanin (d2-40): A new immunohistochemical marker for reactive follicular dendritic cells and follicular dendritic cell sarcomas. Int J Clin Exp Pathol 1: 276-284, 2008.

44. Mograbi M, Stump MS, Luyimbazi DT, Shakhatreh MH and Grider DJ: Pancreatic inflammatory pseudotumor-like follicular dendritic cell tumor. Case Rep Pathol 2019: 2648123, 2019.

45. Bushan K: Follicular dendritic cell sarcoma mediastinum-a case report. Indian J Surg Oncol 5: 290-292, 2014.

46. Prakasan AM, Prabhu AJ, Velarasan K, Backianathan S and Ram TS: Paraneoplastic pemphigus associated with follicular dendritic cell tumor in the mediastinum. Case Rep Dermatol Med 2016: 6901539, 2016

47. Vardas K, Manganas D, Papadimitriou G, Kalatzis V, Kyriakopoulos G, Chantziara M, Exarhos D and Drakopoulos S: Splenic inflammatory pseudotumor-like follicular dendritic cell tumor. Case Rep Oncol 7: 410-416, 2014.

48. Zhang X, Zhu C, Hu Y and Qin X: Hepatic inflammatory pseudotumour-like follicular dendritic cell tumor: A case report. Mol Clin Oncol 6: 547-549, 2017.

49. Xuexue S, Nan L, Shan Z, Tingting X, Ruxue X, Dichen L and Zhenzhong F: Clinicopathologic analysis of 10 cases follicular dendritic cell sarcoma. J Clin Exp Pathol 34: 566-568, 2018.

50. Min G, Shi-Hao Z, Jing C and Fang W: Clinicopathological features of inflammatory pseudotumor-like follicular dendritic cell sarcoma. J Diag Pathol 26: 432-435, 2019.

51. Qi D, Xiaoqi Y, Yuqing C and Jianchen F: Follicular dendritic cell sarcoma: 6 cases report and literature review. Zhejiang Practical Med 23: 274-277, 2018

52. Xiaofei C, Juan W, Qingxin X, Fangfang G, Zhandong Z Shuke Z, Yanyan L, Jianbo Z and Ling M: Clinicopathological analysis of colon follicular dentritic cell sarcomawith metastasis. J Basic Clin Oncol 30: 209-212, 2017.

53. Yong-Ta H and Xiang-Lan M: Clinicopathologic features of follicular dendritic cell sarcoma and its relation with EB virus infection. Chin J N Clin Med 10: 110-113, 2017.

54. Lian-Hua Z, Hualiang X, Li L and Juan D: Extranodal follicular dendritic cell sarcoma of the pharyngeal region: A report of 3 cases with review of literature. J Clin Exp Pathol 31: 673-676, 2015.

55. Chen LS and Yang YH: Follicular Dendritic Cell Sarcoma: A Report of 5 Cases and Literature Review. J Hubei Univ Nationalities. Med Ed 31: 24-27+30+93, 2014.

56. Lennert K: Malignant lymphomas other than Hodgkin's disease, histology, Cytology, Ultra structure, Immunology. Springer, Berlin, pp59-64, 1978

57. Monda L, Warnke R and Rosai J: A primary lymph node malignancy with features suggestive of dendritic reticulum cell differentiation: A report of 4 cases. Am J Pathol 122: 562-572, 1986.

58. Wang HT, Xu HY, Zhang R, Liu ZG and Zhang GJ: Interdigitating dendritic cell sarcoma located in the groin: A case report and literature review. J Int Med Res 46: 4791-4799, 2018.

59. Hirji SA, Senturk JC, Hornick J, Sonoda T and Bleday R: A rare case of interdigitating dendritic cell sarcoma of the rectum: Review of histopathology and management strategy. BMJ Case Rep 2017: bcr2017221754, 2017.

60. Griffin GK, Sholl LM, Lindeman NI, Fletcher CD and Hornick JL: Targeted genomic sequencing of follicular dendritic cell sarcoma reveals recurrent alterations in NF-kB regulatory genes. Mod Pathol 29: 67-74, 2016.

61. Go H, Jeon YK, Huh J, Choi SJ, Choi YD, Cha HJ, Kim HJ, Park G, Min S and Kim JE: Frequent detection of BRAF(V600E) mutations in histiocytic and dendritic cell neoplasms. Histopathology 65: 261-272, 2014.

62. Greisman HA, Lu Z, Tsai AG, Greiner TC, Yi HS and Lieber MR: IgH partner breakpoint sequences provide evidence that AID initiates $\mathrm{t}(11 ; 14)$ and $\mathrm{t}(8 ; 14)$ chromosomal breaks in mantle cell and Burkitt lymphomas. Blood 120: 2864-2867, 2012. 
63. De Pas T, Spitaleri G, Pruneri G, Curigliano G, Noberasco C, Luini A, Andreoni B, Testori A and de Braud F: Dendritic cell sarcoma: An analytic overview of the literature and presentation of original five cases. Crit Rev Oncol Hematol 65: 1-7, 2008.

64. Tisch M, Hengstermann F, Kraft K, von Hinüber G and Maier H: Follicular dendritic cell sarcoma of the tonsil: Report of a rare case. Ear Nose Throat J 82: 507-509, 2003.

65. Saygin C, Uzunaslan D, Ozguroglu M, Senocak M and Tuzuner N: Dendritic cell sarcoma: A pooled analysis including 462 cases with presentation of our case series. Crit Rev Oncol Hematol 88: 253-271, 2013.

66. Domínguez-Malagón H, Cano-Valdez AM, Mosqueda-Taylor A and Hes O: Follicular dendritic cell sarcoma of the pharyngeal region: Histologic, cytologic, immunohistochemical, and ultrastructural study of three cases. Ann Diagn Pathol 8: 325-332, 2004.
67. Duan GJ, Wu F, Zhu J, Guo DY, Zhang R, Shen LL, Wang SH, Li Q, Xiao HL, Mou JH and Yan XC: Extranodal follicular dendritic cell sarcoma of the pharyngeal region: A potential diagnostic pitfall, with literature review. Am J Clin Pathol 133: 49-58, 2010.

c) (i) $\ominus$ This work is licensed under a Creative Common

cc) Attribution-NonCommercial-NoDerivatives 4.0 International (CC BY-NC-ND 4.0) License. 